UDC 517.95, 519.6

\title{
Sufficient convergence conditions for positive solutions of linearized two-dimensional sediment transport problem*
}

\author{
A. I. Sukhinov ${ }^{1}$, V. V. Sidoryakina ${ }^{2}$, Andrey A. Sukhinov ${ }^{3 * *}$ \\ ${ }^{1}$ Don State Technical University, Rostov-on-Don, Russian Federation \\ ${ }^{2}$ Taganrog Institute after A.P. Chekhov (branch) of Rostov State University of Economics, Taganrog, Russian \\ Federation \\ ${ }^{3}$ Southern Federal University, Taganrog - Rostov-on-Don, Russian Federation
}

Introduction. The sediment transportation is the one of major processes that defines the magnitude and bottom surface changing rate of water basins. The most commonly used predictable researches in this field are based on mathematical models. Modeling gives possibilities to reduce and in some cases - to eliminate expensive and often dangerous experiments. Spatially one-dimensional models have been usually used to predict changes of water bottom topography. For real water systems with complicated coastal line, the flow vector is generally not orthogonal to the tangent line for the coastline at each of its points. It also may not coincide with the wind stress vector. Therefore, it is necessary to use spatially two-dimensional models of sediment transportation and effective numerical methods to solve many practically important problems associated with the prediction of bottom surface dynamics.

Materials and Methods. The spatially two-dimensional model of sediment transport that satisfies the basic conservation laws (of material balance and momentum), which is a quasilinear parabolic equation, was earlier proposed by the authors (A.I. Sukhinov, A.E. Chistyakov, E.A. Protsenko, and V.V. Sidoryakina). The linear difference schemes were constructed and researched; the model and some practically important problems were solved. However, the theoretical research of the proximity of solutions for the original nonlinear initial-boundary value problem and the linearized continuous problem, on which basis a discrete model (difference scheme) was developed, remained in the shadow. The researching correctness of the linearized problem and the determination of sufficient conditions for positivity of solutions are caused special interest because only positive solutions of this sediment transport problem have physical value within the framework of the considered models.

Research Results. The investigated nonlinear two-dimensional model of sediment transport in the coastal zone of shallow water basins takes into account the following physically significant conditions and parameters: bottom material porosity; critical value of the tangent stress at which bottom material transport is started; turbulent mixing; the dynamically varying bottom geometry; wind currents; and bottom friction. Linearization is carried out on the time grid; nonlinear coefficients of the parabolic equation are taken at the previous step of time grid. Then, a set of problems, connected by the initial data, are solved; final solutions of the linearized initial boundary value problems chain on a uniform time grid were constructed, and thus, the linearization of the initial 2D nonlinear model is carried out in total time interval. Earlier, the authors proved the existence and uniqueness of the linear problem solution. A priori proximity estimates for the solutions of linearising sequence of boundary value problems and initial non-linear task have been also obtained. Conditions of its positive solution and convergence to the nonlinear sediment transport problem are defined in the norm of the Hilbert space $\mathrm{L}_{1}$ with the rate $\mathrm{O}(\tau)$, where the $\tau$ is a time step.

Discussion and Conclusions. The obtained research results of the spatially two-dimensional nonlinear sediment transport model can be used for predicting the nonlinear hydrodynamic processes, improving their accuracy and reliability due to the availability of new accounting functionality of

\footnotetext{
*The paper was supported by projects No.15-01-08619, No.15-07-08626, No.15-07-08408 of the RFFI and the project No.00-16-13 within the frame of the RAS Presidium Program of Fundamental Research No.I.33P.

***-mail: sukhinov@gmail.com,cvv9@mail.ru, andreysoukhinov@gmail.com
} 
physically important factors, including the specification of the boundary conditions.

Keywords: 2D model of sediment transportation, nonlinear problem, linearized problem, positive solution, convergence in Hilbert space

Introduction. At recent decades the number of papers, devoted to nonlinear boundary value problems, was significantly increased. The emergence of new applications in the field of the ocean and atmosphere physics is contributed to this fact in particular in papers [1-3]. Analytical and numerical approach to investigation of sediment transport problems have been presented in [4,5] for nonlinear case and when partial differential equations with fractional derivatives have been used. Numerical modeling for sediment transport under the wave influence have been presented in papers [6]-[8].

We consider the nonlinear initial-boundary value problem for the spatially two-dimensional model of sediment transportation of shallow water basins and analyzed some qualitative properties of its solutions in this paper.

The research of this problem was performed with using the linearization. For this purpose a grid for time variable was constructed, where the values of nonlinear coefficients are given in the left node of the corresponding time grid. Then the decision of a chain of linear parabolic equations were interconnected to the initial - final data.

Previously the research of the linearized initial-boundary value problem, included the proof of existence and uniqueness of its solution with simultaneous determination of requirements to the classes of smoothness input data, was conducted by the authors [9]. A priori estimation of the proximity of the chain solution of the linearized tasks to the solution of the original nonlinear problem in the norm of the Hilbert space $L_{1}$, depending on the integral estimations of the right side, boundary conditions and norm of initial conditions were also obtained by the authors [9]. At the previous papers the authors constructed and researched a stable conservative difference scheme, which is numerically implemented to the model and real problems of the coastal zone of White Sea for the linearized problem of sediment transport [10]-[12]. In this paper we defined sufficient conditions for positive solutions of linearized problems and their convergence to the solution of the original nonlinear initial-boundary value problem of sediment transport in the norm of the Hilbert space $L_{l}$ was carried out, when the value of time step tends to zero, where the time step is the parameter of grid on which the linearization was carried out.

1. The formulation of the nonlinear initial-boundary value problem for two-dimensional models of sediment transport. Let's consider the equation of sediment transport according to the [4]:

$$
(1-\varepsilon) \cdot \frac{\partial H}{\partial t}=\operatorname{div}\left(k \cdot \frac{\tau_{b c}}{\sin \varphi_{0}} \cdot \operatorname{grad} H\right)-\operatorname{div}\left(k \cdot \vec{\tau}_{b}\right),
$$

where $H=H(x, y, t)$ is the water depth; $\varepsilon$ is the porosity of bottom materials; $\vec{\tau}_{b}$ is the vector of tangential stress at the water bottom; $\tau_{b c}$ is a critical value of the tangential stress; $\tau_{b c}=a \sin \varphi_{0}, \varphi_{0}$ is an angle of bottom relief; $k=k(H, x, y, t)$ is the nonlinear coefficient, determined by the ratio:

$$
k \equiv \frac{\mathrm{A} \tilde{\omega} \mathrm{d}}{\left(\left(\rho_{1}-\rho_{0}\right) g d\right)^{\beta}} \cdot\left|\vec{\tau}_{b}-\frac{\tau_{b c}}{\sin \varphi_{0}} \cdot \operatorname{grad} H\right|^{\beta-1},
$$


where $\rho_{1}, \rho_{0}$ are the density of bottom material particles and water respectively; $g$ is the gravity acceleration; $\tilde{\omega}$ is the wave frequency; $A$ and $\beta$ are the dimensionless constants; $d$ are characteristic dimensions of the bottom material particles.

Let's $D \subset R^{n}$ is domain, where a process occurs, and $S$ is boundary with a piecewise smooth board line. We considered a cylinder $L_{T}=D \times(0, T)$ of height $T$ with the base $D$ as the definitional domain of the equation (1). Its border consists of the lateral surface $S \times[0, T]$ and two bases: the upper basis $\bar{D} \times\{0\}$ and the lower basis $\bar{D} \times\{T\}$. Further, for simplicity, the equation (1) was considered in a rectangular domain $D(x, y)=\left\{0<x<L_{x}, 0<y<L_{y}\right\}$.

We added the initial condition to the equation (1), assuming that the initial conditions of function belong to the corresponding class of smoothness:

$$
H(x, y, 0)=H_{0}(x, y), H_{0}(x, y) \in C^{2}(D) \cap C(\bar{D}), \operatorname{grad}_{(x, y)} H_{0} \in C(\bar{D}),(x, y) \in \bar{D} .
$$

The conditions on the border domain $\bar{D}$ is following:

$$
\begin{gathered}
\left.\left|\overrightarrow{\tau_{b}}\right|\right|_{y=0}=0, \\
H\left(L_{x}, y, t\right)=H_{2}(y, t), 0 \leq y \leq L_{y}, \\
H(0, y, t)=H_{1}(y, t), 0 \leq y \leq L_{y}, \\
H(x, 0, t)=H_{3}(x), 0 \leq x \leq L_{x}, \\
H\left(x, L_{y}^{\prime}, t\right)=H_{4}(x, t), 0 \leq x \leq L_{x}, L_{y}^{\prime}<L_{y} .
\end{gathered}
$$

In addition to the boundary conditions (5)-(8), we assume the fulfillment of their smoothness conditions - the existence of continuous derivatives on the boundary of the domain $\bar{D}$ :

$$
\operatorname{grad}_{(x, y)} H \in C\left(\bar{Ц}_{T}\right) \cap C^{1}\left(Ц_{T}\right)
$$

We consider that there's a liquid layer of finite thickness always in this area and occur for the specified time interval at no drainage area, i.e.

$$
H(x, y, t) \geq c_{0} \equiv \text { const }>0,0 \leq x \leq L_{x}, 0 \leq y \leq L_{y}^{\prime}, 0 \leq t \leq T .
$$

The condition of non-degeneracy of the operator has the form:

$$
k \geq k_{0}=\text { const }>0, \forall(x, y) \in \bar{D}, 0<t \leq T .
$$

The vector of tangential stress at the bottom is calculated using the coordinate basis vectors of the Cartesian coordinate system:

$$
\bar{\tau}_{b}=\bar{i}_{b x}+\bar{j} \tau_{b y}, \tau_{\mathrm{bx}}=\tau_{\mathrm{bx}}(\mathrm{x}, \mathrm{y}, \mathrm{t}), \tau_{\mathrm{by}}=\tau_{\mathrm{by}}(\mathrm{x}, \mathrm{y}, \mathrm{t}) .
$$

2. Linearization of nonlinear initial-boundary value problem of sediment transport. We constructed the uniform time grid $\omega_{\tau}$ with the time step $\tau$ (i.e. the set of points $\left.\omega_{\tau}=\left\{t_{n}=n \cdot \tau, n=0,1, \ldots, N, N \cdot \tau=T\right\}\right)$ to obtain a linearized model on the time interval $0 \leq t \leq T$.

We performe the linearization of the specified initial-boundary value problem using the constructed uniform time grid. The linearization of the member $\operatorname{div}\left(k \cdot \frac{\tau_{b c}}{\sin \varphi_{0}} \cdot \operatorname{gradH}\right)$ (the coefficient $k$ ) 
was performed with using the determination of its values at the time moment $t=t_{n}, n=0,1, \ldots, N$ and consideration of the equation (1) on the time interval $t_{n}<t \leq t_{n+1}, n=0,1,2, \ldots, N-1$.

It is assumed that we know the function $H^{(n)}\left(x, y, t_{n-1}\right) \equiv H^{(n-1)}\left(x, y, t_{n-1}\right)$ and its partial derivatives at spatial variables.

In the case, if $n=1$, it is enough to take the function with the initial conditions $H^{(1)}\left(x, y, t_{0}\right)$, i.e. $H^{(1)}\left(x, y, t_{0}\right) \equiv H_{0}(x, y)$. If $n=2, \ldots, N$, the function $H^{(n)}\left(x, y, t_{n-1}\right)=H^{(n-1)}\left(x, y, t_{n-1}\right)$ is assumed to be known, since it is assumed that the problem (1)-(14) for the previous time interval $t_{n-2}<t \leq t_{n-1}$ is solved.

We introduce the following designation:

$$
k^{(n-1)} \equiv \frac{\mathrm{A} \tilde{\omega} \mathrm{d}}{\left(\left(\rho_{1}-\rho_{0}\right) g d\right)^{\beta}} \cdot\left|\bar{\tau}_{b}-\frac{\tau_{b c}}{\sin \varphi_{0}} \cdot \operatorname{gradH} H^{(n-1)}\left(x, y, t_{n-1}\right)\right|^{\beta-1}, n=1,2, \ldots, N .
$$

Then the equation (1) after linearization may be written in the form:

$$
(1-\varepsilon) \cdot \frac{\partial H^{(n)}}{\partial t}=\operatorname{div}\left(k^{(n-1)} \cdot \frac{\tau_{b c}}{\sin \varphi_{0}} \cdot \operatorname{grad} H^{(n)}\right)-\operatorname{div}\left(k^{(n-1)} \cdot \bar{\tau}_{b}\right), \mathrm{t}_{n-1}<t \leq \mathrm{t}_{n}, n=1, \ldots, N,
$$

with the initial conditions:

$$
H^{(1)}\left(x, y, t_{0}\right)=H_{0}(x, y), H^{(n)}\left(x, y, t_{n-1}\right)=H^{(n-1)}\left(x, y, t_{n-1}\right),(x, y) \in \bar{D}, n=2, \ldots, N .
$$

The equation component $\operatorname{div}\left(k^{(n-1)} \cdot \bar{\tau}_{b}\right)$ is the known function of the right side at such linearization. The boundary conditions (4)-(8) are defined for all time intervals $t_{n-1}<t \leq t_{n}, n=1,2, \ldots, N$.

It should be noted that the coefficients $k^{(n-1)}, n=1,2, \ldots, N$ depend on the spatial variables $x, y$ and the fixed time variable value $t_{n-1}, n=1,2, \ldots, N$, that are defined by the choice of the interval $\tau$ on the grid $\omega_{\tau}$, i.e. $k^{(n-1)}=k^{(n-1)}\left(x, y, t_{n-1}\right), n=1,2, \ldots, N$.

3. The positive solutions of the linearized initial-boundary value problem of sediment transport. The existence and uniqueness of the solution of the linearized problem (14) with the initial conditions (15) and boundary conditions (4)-(8) are proved authors previously. We defined the solution of the linearized problem using $\tilde{H}(x, y, t),(x, y) \in \bar{D}$. The solution $\tilde{H}(x, y, t),(x, y) \in \bar{D}$ depends on the interval $\tau$ on the grid $\omega_{\tau}=\left\{t_{n}=n \cdot \tau, n=0,1, \ldots, N, N \cdot \tau=T\right\}$. Essentially, there're the set of solutions $\left\{\tilde{H}^{(n)}(x, y, t)\right\}, n=1,2, \ldots, N$, depending on a parameter $\tau$. Let's make sure of the positive solutions of this linearized problem.

To define a positive solution of the considered initial-boundary value problem we considered the function $\tilde{H}^{(n)}(x, y, t), t_{n-1}<t \leq t_{n}, n=1,2, \ldots, N \quad$ on $\quad$ the $\quad C^{2}\left(L_{T}\right) \cap C\left(\bar{L}_{T}\right)$, $\operatorname{grad}_{(x, y)} \tilde{H}^{(n)} \in C\left(\bar{Ц}_{T}\right)$ that satisfies the equation (14) with initial and boundary conditions (4)-(8), (15), for which $\tilde{H}^{(n)}(x, y, t) \geq c_{0}>0, c_{0}=$ const, $n=1,2, \ldots, N$ at any $n=1,2, \ldots, N$.

We assumed that the condition for right side function of the equation (14) is following:

$$
\operatorname{div}\left(k^{(n-1)} \cdot \bar{\tau}_{b}\right)<0
$$


and the positivity of the initial conditions may be formulated (15):

$$
H_{0}(x, y), \geq c_{0} \equiv \text { const }>0,(x, y) \in \bar{D}
$$

as well as for boundary conditions (5)-(8):

$$
H_{1}(y, t), H_{2}(y, t), H_{3}(y, t), H_{4}(y, t) \geq c_{0} \equiv \text { const }>0 \text {. }
$$

Firstly, we considered the case $n=1$, for which there's a unique solution of the equation (14). We defined this solution as $\tilde{H}^{(1)}(x, y, t)$. This decision belongs to the class $C^{2}\left(L_{t_{1}}\right) \cap C\left(\bar{L}_{t_{1}}\right)$, $\operatorname{grad}_{(x, y)} \tilde{H}^{(1)} \in C\left(\bar{L}_{t_{1}}\right)$.

Let's suppose that the function $\tilde{H}^{(1)}(x, y, t)$ achieve its minimum value $c_{0}$ or the value which is less than it at some inner point of the parallelepiped $P_{1}=\bar{D} \times\left[0, t_{1}\right]$, or at the point of its "top cover". Then this condition contradicts of the maximum (minimum) principle: the solution of the initialboundary value problem cannot achieved the extremum, including the minimum at the inner point of the domain $P_{1}=\bar{D} \times\left[0, t_{1}\right]$ and on its "top cover" where at all points other than those of the lateral surface $S \times\left[0, t_{1}\right]$ of a parallelepiped $P_{1}=\bar{D} \times\left[0, t_{1}\right]$ (Fig. 1); we defined the solution of the initialboundary value problem for the equation (14) at $n=1$ [13].

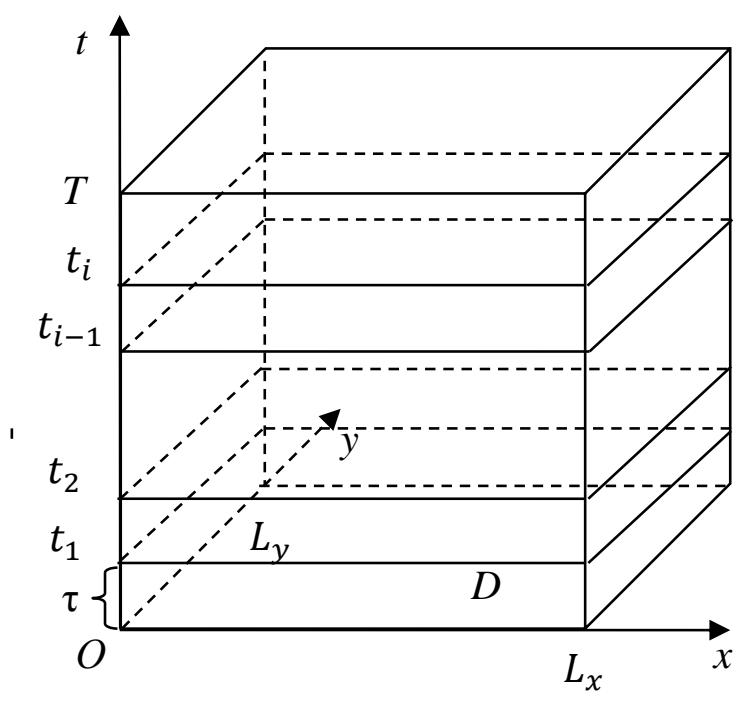

Fig.1. Computational domain

Thus, the function $\tilde{H}^{(1)}(x, y, t)$ achieve to the extremum, including minimum, on the lower base $\bar{D} \times\{0\}$ of the parallelepiped $P_{1}=\bar{D} \times\left[0, t_{1}\right]$ or on its lateral borders $S \times\left[0, t_{1}\right]$, i.e.:

$$
\tilde{H}^{(1)}(x, y, t) \geq \min \left[\min _{(x, y) \in \bar{D}, t=0} \tilde{H}^{(1)}(x, y, t), \min _{(x, y) \in S, 0 \leq t \leq t_{1}} \tilde{H}^{(1)}(x, y, t)\right] .
$$

According to the conditions (17), (18), we obtained the following:

$$
\min _{(x, y) \in \bar{D}, t=0} \tilde{H}^{(1)}(x, y, t)=c_{0}>0, \min _{(x, y) \in S, 0 \leq t \leq t_{1}} \tilde{H}^{(1)}(x, y, t)=c_{0}>0
$$

and

$$
\tilde{H}^{(1)}(x, y, t) \geq c_{0} \equiv \text { const }>0
$$


Thus, the final solution $\tilde{H}^{(1)}(x, y, t)$ for $0<t \leq t_{1}$ will be positive and greater than $c_{0}$.

In the case of $n=2$ we have the initial-boundary value problem with the initial condition $H^{(2)}\left(x, y, t_{1}\right) \equiv H^{(1)}\left(x, y, t_{1}\right)$ with the same smoothness as the initial condition for equation (14) of $n=1$ . Similarly, the solution of the equation (14) $t_{1}<t \leq t_{2}$ exists and is the unique. We define this solution

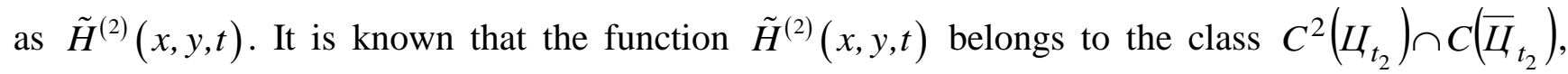
$\operatorname{grad}_{(x, y)} \tilde{H}^{(2)} \in C\left(\bar{L}_{t_{2}}\right)$.

It is obvious that the solution $\tilde{H}^{(2)}(x, y, t)$ of the second problem of the chain of the initialboundary value problems in the form (4)-(8), (14), (15) achieves its minimum value $c_{0}$ or less than $c_{0}$ in some internal point of the parallelepiped $P_{2}=\bar{D} \times\left[t_{1}, t_{2}\right]$ or at the point of its "top cover", which contradicts the principle of maximum (minimum). Then, the solution $\tilde{H}^{(2)}(x, y, t)$ of the initialboundary value problem achieves the extremum on the lower base of the specified parallelepiped or its lateral boundaries $S \times\left[t_{1}, t_{2}\right]$, and so the following inequality is true:

$$
H^{(2)}(x, y, t) \geq c_{0} \equiv \text { const }>0 .
$$

It follows that the solution $\tilde{H}^{(1)}(x, y, t)$ for $0<t \leq t_{1}$ will be positive and more than the value $c_{0}$.

At any $n=k, k=1,2, \ldots, N$ we get a mixed problem for the linear parabolic equations, which having the sufficient smoothness of the initial and boundary conditions. For any number $k, k=1,2, \ldots, N$ the solution of the function $\tilde{H}^{(k)}(x, y, t), t_{k-1}<t \leq t_{k}, k=1,2, \ldots, N$ of the class

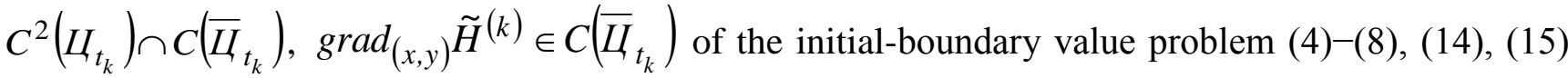
in the parallelepiped $P_{k}=\bar{D} \times\left[t_{k-1}, t_{k}\right]$ achieves the extremum at the bottom of the parallelepiped or on its lateral borders, where due to the conditions $(17)-(18)$ the following is true:

$$
\tilde{H}^{(k)}(x, y, t) \geq c_{0} \equiv \text { const }>0, k, k=1,2, \ldots, N .
$$

We are coming to next theorem taking into account the estimations (20)-(22).

Theorem 1. Let's assume that the equations (14) is in the form:

$$
(1-\varepsilon) \cdot \frac{\partial H^{(n)}}{\partial t}=\operatorname{div}\left(k^{(n-1)} \cdot \frac{\tau_{b c}}{\sin \varphi_{0}} \cdot \operatorname{grad} H^{(n)}\right)-\operatorname{div}\left(k^{(n-1)} \cdot \vec{\tau}_{b}\right), \mathrm{t}_{n-1}<t \leq \mathrm{t}_{n}, n=1,2, \ldots, N,
$$

at $\bigsqcup_{T}=\bar{D} \times(0, T), D \subset R^{n}$,

where $k^{(n-1)} \equiv \frac{\mathrm{A} \tilde{\omega} \mathrm{d}}{\left(\left(\rho_{1}-\rho_{0}\right) g d\right)^{\beta}} \cdot\left|\vec{\tau}_{b}-\frac{\tau_{b c}}{\sin \varphi_{0}} \cdot \operatorname{grad} H^{(n-1)}\left(x, y, t_{n-1}\right)\right|^{\beta-1}, \operatorname{div}\left(k^{(n-1)} \bar{\tau}_{b}\right)<0$, with the initial conditions $\quad H^{(1)}\left(x, y, t_{0}\right)=H_{0}(x, y), H^{(n)}\left(x, y, t_{n-1}\right)=H^{(n-1)}\left(x, y, t_{n-1}\right), \quad(x, y) \in \bar{D}, n=2, \ldots, N, \quad$ and boundary conditions (4)-(8), corresponded to the conditions $(17)-(18)$.

Thus, if $k^{(n-1)} \geq k_{0}>0, k^{(n-1)} \in C^{1}(\bar{D})$, the solution $\tilde{H}^{(n)}(x, y, t), t_{n-1}<t \leq t_{n}, n=1,2, \ldots, N$ of the equation of the number $n$ in the cylinder $L_{T}=\bar{D} \times(0, T)$ is positive and satisfy to estimation for any $n=1,2, \ldots, N$ :

$$
\tilde{H}^{(n)}(x, y, t) \geq c_{0}=\text { const }>0, \quad t_{n-1}<t \leq t_{n}, n=1,2, \ldots, N .
$$


4. Convergence of solutions of the linearized problem to the solution of nonlinear initialboundary value problem. Let's make sure that the solution of the linearized problem tends to the solution of the nonlinear problem in the Hilbert space norm $L_{1}(D)$ when $\tau \rightarrow 0, N \cdot \tau=T$. For this, we denote the solution of the nonlinear problem as $H(x, y, t),(x, y) \in \bar{D}$, and the solution of the linearized problem as $\tilde{H}(x, y, t),(x, y) \in \bar{D}$. We assume that the function $H(x, y, t)$ is defined on the interval $0<t \leq T$, and there're all limited partial derivatives of the appropriate orders on spatial variables and time variable $t$ for the functions $H(x, y, t), \tilde{H}(x, y, t)$, for all $(x, y) \in D, 0<t \leq T$ :

$$
\frac{\partial}{\partial x}\left(\operatorname{grad}\left(\frac{\partial H}{\partial t}\right)\right), \frac{\partial}{\partial y}\left(\operatorname{grad}\left(\frac{\partial H}{\partial t}\right)\right), \frac{\partial}{\partial x}\left(\operatorname{grad}\left(\frac{\partial \tilde{H}}{\partial t}\right)\right), \frac{\partial}{\partial y}\left(\operatorname{grad}\left(\frac{\partial \tilde{H}}{\partial t}\right)\right) .
$$

It should be noted that the function $\tilde{H}(x, y, t)$ is limited at each time interval $t_{n-1}<t \leq t_{n}, n=1,2, \ldots, N$, as it is the solution of the linear initial-boundary value problem for parabolic equation with "smooth" input data.

Let's return to the nonlinear problem (1)-(8). After the substitution of the decision function $H(x, y, t)$ in equation (1) we have:

$$
(1-\varepsilon) \cdot \frac{\partial H}{\partial t}=\operatorname{div}\left(k \cdot \frac{\tau_{b c}}{\sin \varphi_{0}} \cdot \operatorname{gradH}\right)-\operatorname{div}\left(k \cdot \bar{\tau}_{b}\right),
$$

where $k \equiv \frac{\mathrm{A} \tilde{\omega} \mathrm{d}}{\left(\left(\rho_{1}-\rho_{0}\right) g d\right)^{\beta}} \cdot\left|\bar{\tau}_{b}-\frac{\tau_{b c}}{\sin \varphi_{0}} \cdot \operatorname{gradH}\right|^{\beta-1}$.

We multiply the both sides of the equation (24) by the function $H(x, y, t),(x, y) \in \bar{D}$ and integrate over the variable $t, 0<t \leq T$ and over the variables $(x, y)$ in the domain $D$. Thus, we get the next:

$$
\begin{gathered}
\int_{0}^{T}\left((1-\varepsilon) \iint_{D} H \cdot \frac{\partial H}{\partial t} d x d y\right) d t= \\
=\int_{0}^{T}\left(\iint_{D} H \cdot \operatorname{div}\left(k \cdot \frac{\tau_{b c}}{\sin \varphi_{0}} \cdot \operatorname{grad} H\right) d x d y\right) d t-\int_{0}^{T}\left(\iint_{D} H \cdot \operatorname{div}\left(k \cdot \bar{\tau}_{b}\right) d x d y\right) d t .
\end{gathered}
$$

After some transformations in the equation (25), we obtaine the following:

$$
\begin{gathered}
\frac{1}{2}(1-\varepsilon) \iint_{D}\left(H^{2}(x, y, T)-H^{2}(x, y, 0)\right) d x d y= \\
=\int_{0}^{T}\left(\iint_{D} H \cdot \operatorname{div}\left(k \cdot \frac{\tau_{b c}}{\sin \varphi_{0}} \cdot \operatorname{grad} H\right) d x d y\right) d t-\int_{0}^{T}\left(\iint_{D} H \cdot \operatorname{div}\left(k \cdot \bar{\tau}_{b}\right) d x d y\right) d t .
\end{gathered}
$$

Let's consider the linearized problem. After the substitution of $\tilde{H}(x, y, t)$ into the equation (14) we obtain the following:

$$
(1-\varepsilon) \cdot \frac{\partial \tilde{H}^{(n)}}{\partial t}=\operatorname{div}\left(\tilde{k}^{(n-1)} \cdot \frac{\tau_{b c}}{\sin \varphi_{0}} \cdot \operatorname{grad} \tilde{H}^{(n)}\right)-\operatorname{div}\left(\tilde{k}^{(n-1)} \cdot \bar{\tau}_{b}\right), \mathrm{t}_{n-1}<t \leq \mathrm{t}_{n}, n=1, \ldots, N,
$$

where $\tilde{k}^{(n-1)} \equiv \frac{\mathrm{A} \tilde{\omega} \mathrm{d}}{\left(\left(\rho_{1}-\rho_{0}\right) g d\right)^{\beta}} \cdot\left|\bar{\tau}_{b}-\frac{\tau_{b c}}{\sin \varphi_{0}} \cdot \operatorname{grad} \tilde{H}^{(n-1)}\right|^{\beta-1}$. 
We multiply the both sides of the equation (27) by function $\widetilde{H}^{(n)}=\widetilde{H}^{(n)}(x, y, t),(x, y) \in \bar{D}$, and integrate both parts of this equation in the domain $D$, and then by the variable $t, t_{n-1}<t \leq t_{n}$ we obtain the following:

$$
\begin{gathered}
\int_{t_{n-1}}^{t_{n}}\left((1-\varepsilon) \iint_{D} \tilde{H}^{(n)} \cdot \frac{\partial \tilde{H}^{(n)}}{\partial t} d x d y\right) d t= \\
=\int_{t_{n-1}}^{t_{n}}\left(\iint_{D} \tilde{H}^{(n)} \cdot \operatorname{div}\left(\tilde{k}^{(n-1)} \cdot \frac{\tau_{b c}}{\sin \varphi_{0}} \cdot \operatorname{grad} \tilde{H}^{(n)}\right) d x d y\right) d t-\int_{t_{n-1}}^{t_{n}}\left(\iint_{D} \tilde{H}^{(n)} \cdot \operatorname{div}\left(\tilde{k}^{(n-1)} \cdot \bar{\tau}_{b}\right) d x d y\right) d t .
\end{gathered}
$$

After summing the both parts of equation (28), over $n, n=1, \ldots, N$ we obtain the following:

$$
\begin{gathered}
\iint_{D}(1-\varepsilon)\left(\sum_{n=1}^{N} \int_{t_{n-1}}^{t_{n}} \tilde{H}^{(n)} \cdot \frac{\partial \tilde{H}^{(n)}}{\partial t} d t\right) d x d y= \\
=\sum_{n=1}^{N}\left[\int_{t_{n-1}}^{t_{n}}\left(\iint_{D} \tilde{H}^{(n)} \cdot \operatorname{div}\left(\tilde{k}^{(n-1)} \cdot \frac{\tau_{b c}}{\sin \varphi_{0}} \cdot \operatorname{grad} \tilde{H}^{(n)}\right) d x d y\right) d t-\int_{t_{n-1}}^{t_{n}}\left(\iint_{D} \tilde{H}^{(n)} \cdot \operatorname{div}\left(\tilde{k}^{(n-1)} \cdot \bar{\tau}_{b}\right) d x d y\right) d t .\right.
\end{gathered}
$$

After converting the left part of equation (29), we obtain:

$$
\begin{gathered}
\frac{1}{2}(1-\varepsilon) \iint_{D}\left(\tilde{H}^{2}(x, y, T)-\tilde{H}^{2}(x, y, 0)\right) d x d y= \\
=\sum_{n=1}^{N}\left[\int_{t_{n-1}}^{t_{n}}\left(\iint_{D} \tilde{H}^{(n)} \cdot \operatorname{div}\left(\tilde{k}^{(n-1)} \cdot \frac{\tau_{b c}}{\sin \varphi_{0}} \cdot \operatorname{grad} \tilde{H}^{(n)}\right) d x d y\right) d t-\int_{t_{n-1}}^{t_{n}}\left(\iint_{D} \tilde{H}^{(n)} \cdot \operatorname{div}\left(\tilde{k}^{(n-1)} \cdot \bar{\tau}_{b}\right) d x d y\right) d t\right] .
\end{gathered}
$$

After subtraction from the equality (30) the expression (26) and taking into account $H(x, y, 0)=\tilde{H}(x, y, 0)$, we obtain:

$$
\begin{gathered}
\frac{1}{2}(1-\varepsilon) \iint_{D}\left(H^{2}(x, y, T)-\tilde{H}^{2}(x, y, T)\right) d x d y= \\
=\int_{0}^{T}\left(\iint_{D} \tilde{H} \cdot \operatorname{div}\left(k \cdot \frac{\tau_{b c}}{\sin \varphi_{0}} \cdot \operatorname{gradH}\right) d x d y\right) d t-\int_{0}^{T}\left(\iint_{D} H \cdot \operatorname{div}\left(k \cdot \bar{\tau}_{b}\right) d x d y\right) d t- \\
-\sum_{n=1}^{N}\left[\int_{t_{n-1}}^{t_{n}}\left(\iint_{D} \tilde{H}^{(n)} \cdot \operatorname{div}\left(\tilde{k}^{(n-1)} \cdot \frac{\tau_{b c}}{\sin \varphi_{0}} \cdot \operatorname{grad} \tilde{H}^{(n)}\right) d x d y\right) d t-\int_{t_{n-1}}^{t_{n}}\left(\iint_{D} \tilde{H}^{(n)} \cdot \operatorname{div}\left(\tilde{k}^{(n-1)} \cdot \bar{\tau}_{b}\right) d x d y\right) d t\right]
\end{gathered}
$$

Let's change the right side of the equation (31). For this, we add and then subtract the expressions $\tilde{H}^{(n)} \cdot \operatorname{div}\left(k \cdot \frac{\tau_{b c}}{\sin \varphi_{0}} \cdot \operatorname{gradH}\right), \tilde{H}^{(n)} \cdot \operatorname{div}\left(k \cdot \bar{\tau}_{b}\right)$ in the integral expressions. After combining the items, we obtained:

$$
\begin{gathered}
\frac{1}{2}(1-\varepsilon) \iint_{D}\left(H^{2}(x, y, T)-\tilde{H}^{2}(x, y, T)\right) d x d y= \\
=\sum_{n=1}^{N}\left[\int_{t_{n-1}}^{t_{n}}\left(\iint_{D}\left(H-\tilde{H}^{(n)}\right) \cdot \operatorname{div}\left(k \cdot \frac{\tau_{b c}}{\sin \varphi_{0}} \cdot \operatorname{grad} H\right) d x d y\right)+\right. \\
+\iint_{D} \tilde{H}^{(n)} \cdot \operatorname{div}\left(\frac{\tau_{b c}}{\sin \varphi_{0}} \cdot\left(k \cdot \operatorname{grad} H-\tilde{k}^{(n-1)} \cdot \operatorname{grad} \tilde{H}^{(n)}\right)\right) d x d y+ \\
\left.\left.+\iint_{D}\left(\tilde{H}^{(n)}-H\right) \cdot \operatorname{div}\left(k \cdot \bar{\tau}_{b}\right) d x d y+\iint_{D} \tilde{H}^{(n)} \cdot \operatorname{div}\left(\left(\tilde{k}^{(n-1)}-k\right) \cdot \bar{\tau}_{b}\right) d x d y\right) d t\right]
\end{gathered}
$$

Further we'll evaluate each integral on the right side of equality (32). We introduce the following expressions: 


$$
\begin{aligned}
& I_{1}^{n}=\int_{t_{n-1}}^{t_{n}}\left(\iint_{D}\left(H-\tilde{H}^{(n)}\right) \cdot \operatorname{div}\left(k \cdot \frac{\tau_{b c}}{\sin \varphi_{0}} \cdot \operatorname{gradH}\right) d x d y\right) d t, \\
& I_{2}^{n}=\int_{t_{n-1}}^{t_{n}}\left(\iint_{D} \tilde{H}^{(n)} \cdot \operatorname{div}\left(\frac{\tau_{b c}}{\sin \varphi_{0}}\left(k \cdot \operatorname{grad} H-\tilde{k}^{(n-1)} \cdot \operatorname{grad} \tilde{H}^{(n)}\right)\right) d x d y\right) d t, \\
& I_{3}^{n}=\int_{t_{n-1}}^{t_{n}}\left(\iint_{D}\left(\tilde{H}^{(n)}-H\right) \cdot \operatorname{div}\left(k \cdot \bar{\tau}_{b}\right) d x d y\right) d t \\
& I_{4}^{n}=\int_{t_{n-1}}^{t_{n}}\left(\iint_{D} \tilde{H}^{(n)} \cdot \operatorname{div}\left(\left(\tilde{k}^{(n-1)}-k\right) \cdot \bar{\tau}_{b}\right) d x d y\right) d t, n=1, \ldots, N .
\end{aligned}
$$

Assuming $n=1$ in the equations (33)-(36), we consider the integrals on the first time interval $t_{0}<t \leq t_{1}$.

Firstly, we evaluated the integral $I_{1}^{1}$. Using the expansion of functions $H(x, y, t)$ and $\tilde{H}^{(1)}(x, y, t)$, according to the Taylor formula with respect to $\left(t-t_{0}\right)$ with the remainder term in the Lagrange form, and taking into account the condition (3), we obtained:

$$
H(x, y, t)-\tilde{H}^{(1)}(x, y, t)=\left(\frac{\partial H\left(x, y, \xi_{1}\right)}{\partial t}-\frac{\partial \tilde{H}^{(1)}\left(x, y, \xi_{2}\right)}{\partial t}\right) \cdot\left(t-t_{0}\right),
$$

where $t_{0}<\xi_{1} \leq t_{1}, t_{0}<\xi_{2} \leq t_{1}, t_{0}<t \leq t_{1}$.

Using the equality (37), we obtained the expression for the integral $I_{1}^{1}$ :

$$
\begin{gathered}
I_{1}^{1}=\int_{t_{0}}^{t_{1}} d t\left(\iint_{D}\left(H-\tilde{H}^{(1)}\right) \cdot \operatorname{div}\left(k \cdot \frac{\tau_{b c}}{\sin \varphi_{0}} \cdot \operatorname{gradH}\right) d x d y\right)= \\
=\int_{t_{0}}^{t_{1}}\left(t-t_{0}\right) \cdot\left(\iint_{D}\left(\frac{\partial H\left(x, y, \xi_{1}\right)}{\partial t}-\frac{\partial \tilde{H}^{(1)}\left(x, y, \xi_{2}\right)}{\partial t}\right) \operatorname{div}\left(k \cdot \frac{\tau_{b c}}{\sin \varphi_{0}} \cdot \operatorname{gradH}\right) d x d y\right) d t .
\end{gathered}
$$

Taking into account the inequality $t-t_{0}=\tau \leq$ and (38), we are coming to estimation:

$$
I_{1}^{1} \leq \frac{1}{2} \cdot \tau^{2} \cdot L_{x} \cdot L_{y} \cdot M_{1}^{1},
$$

where

$$
M_{1}^{1} \equiv \max _{t_{0} \leq t \leq t_{1}}\left\{\max _{(x, y) \in \bar{D}}\left|\left(\frac{\partial H\left(x, y, \xi_{1}\right)}{\partial t}-\frac{\partial \tilde{H}^{(1)}\left(x, y, \xi_{2}\right)}{\partial t}\right) \cdot \operatorname{div}\left(k \cdot \frac{\tau_{b c}}{\sin \varphi_{0}} \cdot \operatorname{grad} H\right)\right|\right\} .
$$

Then, the estimation for the integral $I_{2}^{1}$ will be obtained. It should be noted that the following equality is true:

$$
\begin{gathered}
\operatorname{div}\left(k \cdot \frac{\tau_{b c}}{\sin \varphi_{0}} \cdot \operatorname{grad} H\right)-\operatorname{div}\left(\tilde{k}^{(0)} \cdot \frac{\tau_{b c}}{\sin \varphi_{0}} \cdot \operatorname{grad} \tilde{H}^{(1)}\right)= \\
=\operatorname{div}\left(\left(k-\tilde{k}^{(0)}\right) \cdot \frac{\tau_{b c}}{\sin \varphi_{0}} \cdot \operatorname{grad} H\right)+\operatorname{div}\left(\tilde{k}^{(0)} \cdot \frac{\tau_{b c}}{\sin \varphi_{0}} \cdot\left(\operatorname{grad} H-\operatorname{grad} \tilde{H}^{(1)}\right)\right) .
\end{gathered}
$$

We can see that the integral $I_{2}^{1}$ taking into account the expression (40) can be represented as:

$$
I_{2}^{1}=\int_{t_{0}}^{t_{1}}\left(\iint_{D} \tilde{H}^{(1)} \cdot \operatorname{div}\left(\frac{\tau_{b c}}{\sin \varphi_{0}} \cdot\left(\left(k-\tilde{k}^{(0)}\right) \cdot \operatorname{grad} H+\tilde{k}^{(0)} \cdot\left(\operatorname{grad} H-\operatorname{grad} \tilde{H}^{(1)}\right)\right)\right) d x d y\right) d t .
$$


After functions representations $k(x, y, t), H(x, y, t)$, according to the Taylor formula and using the equalities $k\left(x, y, t_{0}\right)=\tilde{k}^{(0)}\left(x, y, t_{0}\right), H\left(x, y, t_{0}\right)=\tilde{H}^{(1)}\left(x, y, t_{0}\right)$, we have:

$$
\begin{gathered}
k-\tilde{k}^{(0)}=\frac{\partial k\left(x, y, \xi_{3}\right)}{\partial t} \cdot\left(t-t_{0}\right), \\
\operatorname{grad} H-\operatorname{grad} \tilde{H}^{(1)}=\operatorname{grad}\left(\frac{\partial H\left(x, y, \xi_{4}\right)}{\partial t} \cdot\left(t-t_{0}\right)\right),
\end{gathered}
$$

where $t_{0}<\xi_{3} \leq t_{1}, t_{0}<\xi_{4} \leq t_{1}, t_{0}<t \leq t_{1}$.

Using the expressions (42) and (43) for the integral in the formula (41), we get:

$$
I_{2}^{1}=\int_{t_{0}}^{t_{1}}\left(t-t_{0}\right)\left(\iint_{D} \tilde{H}^{(1)} \cdot \operatorname{div}\left(\frac{\tau_{b c}}{\sin \varphi_{0}} \cdot\left(\frac{\partial k\left(x, y, \xi_{3}\right)}{\partial t} \cdot \operatorname{gradH}+\tilde{k}^{(0)} \cdot \operatorname{grad}\left(\frac{\partial H\left(x, y, \xi_{4}\right)}{\partial t}\right)\right) d x d y\right) d t .\right.
$$

Assuming the restrictions of the corresponding derivatives, we introduce a constant value:

$$
M_{2}^{1} \equiv \max _{t_{0} \leq t \leq t_{1}}\left\{\max _{(x, y) \in \bar{D}}\left\{\left|\tilde{H}^{(1)} d i v\left(\frac{\tau_{b c}}{\sin \varphi_{0}}\left(\frac{\partial k\left(x, y, \xi_{3}\right)}{\partial t} \cdot \operatorname{gradH}+\tilde{k}^{(0)} \cdot \operatorname{grad}\left(\frac{\partial H\left(x, y, \xi_{4}\right)}{\partial t}\right)\right)\right) d x d y\right|\right\}\right\} .
$$

Using the notation for the value $M_{2}^{1}$ from the equation (44), we obtain:

$$
I_{2}^{1} \leq \frac{1}{2} \cdot \tau^{2} \cdot M_{2}^{1} \cdot L_{x} \cdot L_{y} .
$$

Fore estimation of the integral $I_{3}^{1}$ we use the equality (37), and we obtain the following:

$$
I_{3}^{1}=\int_{t_{0}}^{t_{1}}\left(t-t_{0}\right) \cdot\left(\iint_{D}\left(\frac{\partial \tilde{H}^{(1)}\left(x, y, \xi_{5}\right)}{\partial t}-\frac{\partial H\left(x, y, \xi_{6}\right)}{\partial t}\right) \cdot \operatorname{div}\left(k \cdot \bar{\tau}_{b}\right) d x d y\right) d t,
$$

where $t_{0}<\xi_{5} \leq t_{1}, t_{0}<\xi_{6} \leq t, t_{0}<t \leq t_{1}$.

We introduce the notation:

$$
M_{3}^{1} \equiv \max _{t_{0} \leq t \leq t_{1}}\left\{\max _{(x, y) \in D}\left|\left(\frac{\partial \tilde{H}^{(1)}\left(x, y, \xi_{5}\right)}{\partial t}-\frac{\partial H\left(x, y, \xi_{6}\right)}{\partial t}\right) \operatorname{div}\left(k \cdot \bar{\tau}_{b}\right)\right|\right\},
$$

after that we can write inequality:

$$
I_{3}^{1} \leq \frac{1}{2} \cdot \tau^{2} \cdot L_{x} \cdot L_{y} \cdot M_{3}^{1}
$$

Then we shall estimate the integral $I_{4}^{1}$. For this, we perform simple transformations of $I_{4}^{1}$ taking into account the expression (42):

$$
I_{4}^{1}=\int_{t_{0}}^{t_{1}}\left(t-t_{0}\right) \cdot\left(\iint_{D} \tilde{H}^{(1)} \cdot d i v \cdot\left(\left(-\frac{\partial k\left(x, y, \xi_{7}\right)}{\partial t}\right) \cdot \bar{\tau}_{b}\right) d x d y\right) d t .
$$

Due to the existence of bounded functions $\tilde{H}^{(1)}(x, y, t), H(x, y, t), \quad t_{0}<t \leq t_{1}$ as well as it's mixed derivatives on spatial and time variables we obtain from (47), the following inequality:

$$
I_{4}^{1} \leq \frac{1}{2} \cdot \tau^{2} \cdot M_{4}^{1} \cdot L_{x} \cdot L_{y}
$$

where

$$
M_{4}^{1} \equiv \max _{t_{0} \leq t \leq t_{1}}\left\{\max _{(x, y) \in D}\left\{\left|\tilde{H}^{(1)} \cdot \operatorname{div}\left(\left(-\frac{\partial k\left(x, y, \xi_{7}\right)}{\partial t}\right) \cdot \bar{\tau}_{b}\right)\right|\right\}\right\}
$$


Taking into account the evaluations, obtained from (39), (45), (46), (48), and using the inequality of the polygon for module values, we are coming to the inequality in the next form

$$
\iint_{D}\left(H^{2}\left(x, y, t_{1}\right)-\tilde{H}^{(1) 2}\left(x, y, t_{1}\right)\right) d x d y \leq \tau^{2} \cdot L_{x} \cdot L_{y} \cdot M_{1}^{*},
$$

where

$$
M_{1}^{*}=\frac{1}{1-\varepsilon} \cdot\left(M_{1}^{1}+M_{2}^{1}+M_{3}^{1}+M_{4}^{1}\right) .
$$

After substitution the functions $H^{2}\left(x, y, t_{1}\right), \tilde{H}^{(1)^{2}}\left(x, y, t_{1}\right)$ and carrying out similar reasoning as the previous one, starting with the equality (24), we can obtain an estimation:

$$
\iint_{D}\left(\tilde{H}^{(1) 2}\left(x, y, t_{1}\right)-H^{2}\left(x, y, t_{1}\right)\right) d x d y \leq \tau^{2} \cdot L_{x} \cdot L_{y} \cdot M_{1}^{*} .
$$

We obtained the following inequality from inequalities (49) and (50):

$$
\iint_{D}\left|\tilde{H}^{(1) 2}\left(x, y, t_{1}\right)-H^{2}\left(x, y, t_{1}\right)\right| d x d y \leq \tau^{2} \cdot L_{x} \cdot L_{y} \cdot M_{1}^{*} .
$$

Let's transform the left part of the inequality (51):

$$
\begin{gathered}
\iint_{D}\left|\tilde{H}^{(1) 2}\left(x, y, t_{1}\right)-H^{2}\left(x, y, t_{1}\right)\right| d x d y= \\
=\iint_{D}\left|\tilde{H}^{(1)}\left(x, y, t_{1}\right)-H\left(x, y, t_{1}\right)\right| \cdot\left|\tilde{H}^{(1)}\left(x, y, t_{1}\right)+H\left(x, y, t_{1}\right)\right| d x d y .
\end{gathered}
$$

Further, we'll assume that the conditions of Theorem 1 and inequalities in the form (23) are fulfilled for the functions $H(x, y, t)$ and $\tilde{H}^{(n)}(x, y, t), n=1,2, \ldots, N$, i.e.:

$$
\begin{aligned}
& H(x, y, t) \geq c_{0}>0,(x, y) \in \bar{D}, \quad 0 \leq t \leq T, \\
& \tilde{H}^{(n)}(x, y, t) \geq c_{0}>0,(x, y) \in \bar{D}, \quad 0 \leq t \leq T .
\end{aligned}
$$

Taking into account the expressions (53), (54), we readily come to inequality:

$$
\iint_{D}\left|\tilde{H}^{(1)^{2}}\left(x, y, t_{1}\right)-H^{2}\left(x, y, t_{1}\right)\right| d x d y \geq 2 c_{0} \cdot \iint_{D}\left|\widetilde{H}^{(1)}\left(x, y, t_{1}\right)-H\left(x, y, t_{1}\right)\right| d x d y .
$$

We obtain the following estimation from formulas (51), (52):

$$
\iint_{D}\left|\tilde{H}^{(1)}\left(x, y, t_{1}\right)-H\left(x, y, t_{1}\right)\right| d x d y \leq \frac{1}{2 c_{0}} \cdot \tau^{2} \cdot L_{x} \cdot L_{y} \cdot M_{1}^{*}
$$

The required estimation for $n=1$ has been received, since the inequality (56) is equivalent to the following:

$$
\left\|\tilde{H}^{(1)}\left(x, y, t_{1}\right)-H\left(x, y, t_{1}\right)\right\|_{L_{1}(D)} \leq \frac{1}{2 c_{0}} \cdot \tau^{2} \cdot L_{x} \cdot L_{y} \cdot M_{1}^{*} .
$$

In fact, the first step in induction proof was made at $n=1$; this includes the sequence of expressions (37)-(57).

Let's take $n=s, s=2, . ., N$. Then by reasoning similar to the previous one we get the following inequality:

$$
\left\|\tilde{H}\left(t^{s}\right)-\tilde{\tilde{H}}\left(t^{s}\right)\right\|_{L_{1}(D)} \leq \frac{1}{2 c_{0}} \cdot \tau^{2} \cdot L_{x} \cdot L_{y} \cdot C \cdot N\left(1+\ldots+\tau^{s-1}\right)
$$

where $C \equiv \max _{(x, y) \in \bar{D}}\left\{M_{1}^{*}, M_{2}^{*}, \ldots, M_{s}^{*}\right\}, M_{1}^{*}, M_{2}^{*}, \ldots, M_{s}^{*}$ are some constant functions that are defined for the time intervals $t_{s}<t \leq t_{s+1}, s=0,1,2, \ldots, N-1$ respectively. 
Since $N=\frac{T}{\tau}$ from inequality (58), we obtained:

$$
\|\tilde{H}(T)-H(T)\|_{L_{1}(D)} \leq \frac{1}{2 c_{0} \cdot(1-\tau)} \cdot \tau \cdot L_{x} \cdot L_{y} \cdot C \cdot T
$$

Taking into account $\tau \rightarrow 0$ (59), we obtained:

$$
\|\tilde{H}(T)-H(T)\|_{L_{1}(D)} \rightarrow 0 \text {. }
$$

It's the proof of convergence of the linearized problem to the solution of the original problem.

Theorem 2. Let's take the given initial-boundary value problem in the next form:

$$
(1-\varepsilon) \frac{\partial H}{\partial t}=\operatorname{div}\left(k \cdot \frac{\tau_{b c}}{\sin \varphi_{0}} \cdot \operatorname{grad} H\right)-\operatorname{div}\left(k \bar{\tau}_{b}\right) \text { в } L_{T}=D \times(0, T), D \subset R^{n} .
$$

where $\quad k \equiv \frac{\mathrm{A} \tilde{\omega} \mathrm{d}}{\left(\left(\rho_{1}-\rho_{0}\right) g d\right)^{\beta}} \cdot\left|\bar{\tau}_{b}-\frac{\tau_{b c}}{\sin \varphi_{0}} \cdot \operatorname{gradH}\right|^{\beta-1}, \operatorname{div}\left(k^{(n-1)} \bar{\tau}_{b}\right)<0$ with the initial conditions (4)-(8) $H(x, y, 0)=H_{0}(x, y), \quad H_{0}(x, y) \in C^{2}(D) \cap C(\bar{D}), \quad \operatorname{grad}_{(x, y)} H_{0} \in C(\bar{D}),(x, y) \in \bar{D} \quad$ on $\quad$ the border domain $\bar{D}$.

The function $H(x, y, t)$ is the problem solution of the class $C^{2}\left(L_{T}\right) \cap C\left(\bar{L}_{T}\right)$,

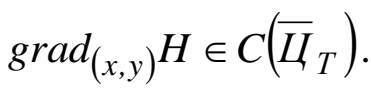

Further, we assumed that the linearized initial-boundary value problem is constructed on the time grid $\omega_{\tau}=\left\{t_{n}=n \cdot \tau, n=0,1, \ldots, N, N \cdot \tau=T\right\}$ :

$$
(1-\varepsilon) \frac{\partial H^{(n)}}{\partial t}=\operatorname{div}\left(k^{(n-1)} \cdot \frac{\tau_{b c}}{\sin \varphi_{0}} \cdot \operatorname{grad} H^{(n)}\right)-\operatorname{div}\left(k^{(n-1)} \cdot \vec{\tau}_{b}\right), n=1,2, \ldots, N .
$$

where $k^{(n-1)} \equiv \frac{\mathrm{A} \tilde{\omega} \mathrm{d}}{\left(\left(\rho_{1}-\rho_{0}\right) g d\right)^{\beta}} \cdot\left|\bar{\tau}_{b}-\frac{\tau_{b c}}{\sin \varphi_{0}} \cdot \operatorname{grad} H^{(n-1)}\left(x, y, t_{n-1}\right)\right|^{\beta-1}$ with the initial conditions:

$$
H^{(1)}\left(x, y, t_{0}\right)=H_{0}(x, y), H^{(n)}\left(x, y, t_{n-1}\right)=H^{(n-1)}\left(x, y, t_{n-1}\right),(x, y) \in \bar{D}, n=2, \ldots, N,
$$

boundary conditions (4)-(8), satisfying (17)-(18).

The function $\tilde{H}(x, y, t)$ is the positive problem solution of the class $C^{2}\left(L_{T}\right) \cap C\left(\bar{L}_{T}\right)$,

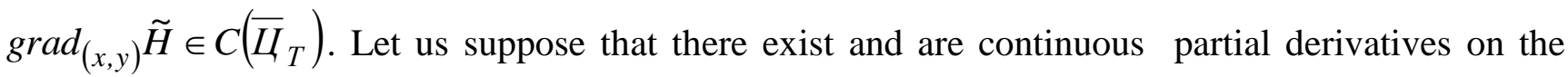
spatial and time variable $t$ for the functions $H(x, y, t), \tilde{H}(x, y, t)$ for $(x, y) \in D, 0<t \leq T$ :

$$
\frac{\partial}{\partial x}\left(\operatorname{grad}\left(\frac{\partial H}{\partial t}\right)\right), \frac{\partial}{\partial y}\left(\operatorname{grad}\left(\frac{\partial H}{\partial t}\right)\right), \frac{\partial}{\partial x}\left(\operatorname{grad}\left(\frac{\partial \tilde{H}}{\partial t}\right)\right), \frac{\partial}{\partial y}\left(\operatorname{grad}\left(\frac{\partial \tilde{H}}{\partial t}\right)\right) .
$$

If $k^{(n-1)} \geq k_{0}>0, k_{0}=$ const $, k^{(n-1)} \in C^{1}(\bar{D}), n=1,2, \ldots, N$, the following inequality takes place :

$$
\|\tilde{H}(T)-H(T)\|_{L_{1}(D)} \leq \frac{1}{2 c_{0} \cdot(1-\tau)} \tau \cdot L_{x} \cdot L_{y} \cdot C \cdot T,
$$


where $C$ is a constant value, greater than 0 , i.e. the positive solution of the linearized problem $\tilde{H}(x, y, t)$ tends to the solution $H(x, y, t)$ of the nonlinear problem in the Hilbert space norm $L_{1}(D)$ when $\tau \rightarrow 0, N \cdot \tau=T$.

Conclusion. We researched the linearized two-dimensional mathematical model of bottom sediment transportation in coastal systems, which satisfies the basic conservation laws and takes into account the following physical processes and parameters: porosity of the bottom material; critical tangential stress, due to which the transportation of bottom materials are occurred; dynamically variable geometry of the bottom surface due to the motion of water medium.

The conditions of positive solutions of the linearized initial-boundary value problems and their convergence to the solution of the original nonlinear initial-boundary value problem in the Hilbert space norm $\mathrm{L}_{1}$ were formulated as sufficient conditions.

\section{References}

1. Marchuk, G.I., Dymnikov, V.P., Zalesny, V.B. Matematicheskie modeli v geofizicheskoy gidrodinamike $i$ chislennye metodyikh realizatsii. [Mathematical models in geophysical hydrodynamics and numerical methods for their implementation.] Leningrad: Gidrometeoizdat, 1987, 296 p. (in Russian).

2. Sukhinov, A.I., Chistyakov, A.E., Alekseenko, E.V. Numerical realization of the threedimensional model of hydrodynamics for shallow water basins on a high-performance system. Mathematical Models and Computer Simulations, 2011, vol. 3, iss. 5, pp. 562-574.

3. Leontyev, I.O. Pribrezhnaya dinamika: volny, techeniya potoki nanosov. [Coastal dynamics: waves, moving streams, deposits drifts.] Moscow: GEOS, 2001, 272 p. (in Russian).

4. Jorge Lorenzo-Trueba, Vaughan R. Voller, Tetsuji Muto, Wonsuck Kim, Chris Paola, John B. Swenson. A similarity solution for a dual moving boundary problem associated with a coastal-plain depositional system. Journal of Fluid Mechanics, 2009, v.628, pp.427-443.

5. J. Lorenzo-Trueba, V.R. Voller. Analytical and numerical solution of a generalized Stefan problem exhibiting two moving boundaries with application to ocean delta formation. Journal of Mathematical Analysis and Applications, 2010, v. 366, pp. 538-549.

6. Sukhinov A.I., Chistyakov A.E., Shishenya A.V., Timofeeva E.F. Mathematical model for calculating coastal wave processes. Mathematical Models and Computer Simulations. 2013, v. 5, iss. 2, pp. 122-129.

7. Xiaoying Liu, et al. Predictive modeling in sediment transportation across multiple spatial scales in the Jialing River Basin of China. International Journal of Sediment Research, 2015, vol. 30, iss. 3, pp. 250-255.

8. Sukhinov, A.I., Chistyakov, A.E., Protsenko, E.A. Mathematical modeling of sediment transport in the coastal zone of shallow reservoirs. Mathematical Models and Computer Simulations, 2014, vol. 6, iss. 4, pp. 351-363.

9. Sukhinov, A.I., Sidoryakina. Well-Posedness Analysis and Numerical Implementation of a Linearized Two-Dimensional Bottom Sediment Transport Problem. Computational Mathematics and Mathematical Physics, 2017, Vol. 57, No. 6, pp. 978-994.

10. Sukhinov, A.I., Chistyakov, A.E. Adaptive modified alternating triangular iterative method for solving grid equations with a non-self-adjoint operator. Mathematical Models and Computer Simulations, 2012, vol. 4, iss. 4, pp. 398-409.

11. Sukhinov, A.I., Chistyakov, A.E., Protsenko, E.A. Matematicheskoe modelirovanie transporta nanosov $v$ pribrezhnykh vodnykh sistemakh na mnogoprotsessornoy vychislitel'noy 
sisteme. [Sediment transport mathematical modeling in a coastal zone using multiprocessor computing systems.] Numerical Methods and Programming, 2014, vol. 15, iss. 4, pp. 610-620 (in Russian).

12. Sukhinov, A.I., et al. Sravnenie vychislitel'nykh effektivnostey yavnoy i neyavnoy skhem dlya zadachi transporta nanosov $v$ pribrezhnykh vodnykh sistemakh. [Comparison of computational efficiency of explicit and implicit schemes.] Numerical Methods and Programming, 2015, vol. 16, iss. 3, pp. 328-338 (in Russian).

13. Godunov, S.K. Uravneniya matematicheskoy fiziki. [Equations of mathematical physics.] $2^{\text {nd }}$ revised and enlarged ed. Moscow: Nauka, 1979, 392 p. (in Russian).

\title{
Autors:
}

Sukhinov Aleksandr I., Dr.Sci. (Phys.-Math.), professor, vice-rector for research and innovation activities Don State Technical University (DSTU) (Russian Federation, 344000, Rostov-on-Don, Gagarin sq., 1)

Sidoriakina Valentines V., Cand.Sci. (Phys.-Math.), associate professor associate professor of the Mathematics Department Taganrog Institute named after A.P. Chekhov (filial) "Rostov State Economic University (RINH)" (Russian Federation, 347936, Rostov region, Taganrog, Initiative Str., 48)

Sukhinov Andrei A., graduate student South Federal University (SFU)

(Russian Federation, 347930, Rostov region, Taganrog, Chekhov Str. 22)

\section{УДК 517.95, 519.6}

\section{Достаточные условия сходимости положительных решений линеаризованной двумерной задачи транспорта наносов ${ }^{*}$}

\author{
А. И. Сухинов ${ }^{1}$, В. В. Сидорякина ${ }^{2}$, Андрей А. Сухинов ${ }^{3 * *}$ \\ ${ }^{1}$ Донской государственный технический университет, г. Ростов-на-Дону, Российская Федерация \\ ${ }^{2}$ Таганрогский институт имени А. П. Чехова (филиал) РГЭУ (РИНХ), г. Таганрог, Российская Федерация \\ ${ }^{3}$ Южный федеральный университет, г. Ростов-на-Дону-Таганрог, Российская Федерация
}

Введение. Транспорт наносов является одним из основных процессов, определяющих величины и темпы деформаций донных поверхностей водных объектов. Чаще всего прогностические исследования в этой области строятся на основе математических моделей, которые позволяют сократить, а в ряде случаев исключить дорогостоящие и опасные в экологическом отношении эксперименты. Для прогнозирования изменения рельефа дна в основном используются пространственно-одномерные модели. Для реальных прибрежных систем со сложной формой берега вектор потока наносов в общем случае не ортогонален касательной к береговой линии в каждой из ее точек. Также он может не совпадать с вектором ветровых напряжений. Поэтому для решения многих практически важных задач, связанных с прогнозированием динамики донной поверхности водоемов, необходимо применение пространственно-двумерных моделей транспорта наносов и эффективных численных методов их реализации.

\footnotetext{
*Работа выполнена при финансовой поддержке РФФИ по проектам № 15-01-08619, 16-07-00100, 15-07-08626, 1507-08408 и по проекту № 00-16-13 в рамках Программы фундаментальных исследований Президиума РАН № I.33П.

***-mail: sukhinov@gmail.com,cvv9@mail.ru, andreysoukhinov@gmail.com
} 
Mатериальь u методь. Авторами (А. И. Сухинов, А. Е. Чистяков, Е. А. Проценко, В. В. Сидорякина) ранее была предложена пространственно-двумерная модель транспорта наносов, удовлетворяющая основным законам сохранения (материального баланса и импульса), которая представляет собой квазилинейное уравнение параболического типа. Были построены и исследованы линейные разностные схемы и решены модельные, а также практические задачи. Однако осталось в тени теоретическое исследование «близости» решений исходной нелинейной начально-краевой и линеаризованной непрерывной задач, на основе которой была построена дискретная модель (разностная схема). Особый интерес представляет исследование корректности линеаризованной задачи и определение достаточных условий положительности решений, т. к. только положительные решения задачи транспорта наносов имеют смысл в рамках рассматриваемых моделей.

Результаты. Исследуемая нелинейная двумерная модель транспорта наносов в прибрежной зоне мелководных водоемов учитывает следующие физически значимые факторы и параметры: пористость грунта; критическое значение касательного напряжения, при котором начинается перемещение наносов; турбулентный обмен; динамически изменяемая геометрия дна; ветровые течения и трение о дно. Линеаризация осуществляется на временной сетке - нелинейные коэффициенты параболического уравнения берутся с запаздыванием на один шаг временной сетки. Далее строится цепочка взаимосвязанных по начальным условиям - финальным решениям цепочки линеаризованных смешанных задач Коши на равномерной временной сетке, и таким образом осуществляется линеаризация в целом $2 D$ нелинейной модели. Ранее авторами были доказаны существование и единственность решения цепочки линеаризованных задач, получена априорная оценка близости решения цепочки линеаризованных задач к решению исходной нелинейной задачи. В данной работе определены условия положительности ее решений и их сходимости к решению нелинейной задачи транспорта наносов в норме Гильбертова пространства $L_{1}$ со скоростью $O(\tau)$, где $\tau$ - временной шаг.

Bblвoдbl. Полученные результаты исследования пространственно-двумерной нелинейной модели транспорта наносов могут быть использованы при прогнозировании нелинейных гидродинамических процессов, повышения их точности и надежности в силу наличия новых функциональных возможностей учета физически важных факторов, в том числе уточнения граничных условий.

Ключевые слова: пространственно-двумерная модель транспорта наносов, прибрежная зона, нелинейная задача, линеаризованная задача, положительность решения

\section{Авторы:}

Сухинов Александр Иванович, доктор физико-математических наук, профессор проректор по НИР и инновационной деятельности Донского государственного технического университета (ДГТУ) (РФ, 344000, г. Ростов-на-Дону, пл. Гагарина,1)

Сидорякина Валентина Владимировна, кандидат физико-математических наук, доцент, доцент кафедры «Математика» Таганрогского института имени А.П. Чехова (филиал) ФГБОУ ВО Ростовского государственного экономического университета (РИНХ) (РФ, 347936, Ростовская обл., г. Таганрог, ул. Инициативная, д. 48)

Сухинов Андрей Александрович, аспирант Южного федерального университета (ЮФУ) (РФ, 347922, Ростовская обл., г. Таганрог, ул. Чехова, д. 22) 